\title{
Funciones de la fotografía en las relaciones interculturales entre familias inmigrantes ${ }^{1}$
}

\section{The functions of Photography in the intercultural relations amongst immigrant families}

\author{
Antonio BAUTISTA GARCIA-VERA, María Rosario LIMÓN MENDIZÁBAL, Pilar \\ OÑATE y GARCÍA DE LA RASILLA, Carmen ROSTAND QUIJADA \\ Universidad Complutense de Madrid
}

Recibido: Mayo 2014

Evaluado: Julio 2014

Aceptado: Julio 2014

\section{Resumen}

En este artículo presentamos los resultados y el análisis de uno de los objetivos del proyecto I+D+i aprobado por el Ministerio de Economía y Competitividad de España titulado Mediaciones audiovisuales en las relaciones entre escuela y familias inmigrantes. Concretamente, el dirigido a conocer las funciones que tienen las imágenes fotográficas en las relaciones de un grupo de padres inmigrantes en el colegio al que asisten sus hijos e hijas. Los datos presentados corresponden a las narraciones biográfico-culturales y visuales iniciadas en las aulas por estas familias junto a la tutora del grupo, y continuadas en sus contextos personal y social. Concluimos que las fotografías en los relatos han tenido las funciones de: fuente de información, soporte de análisis, reflexión y debate y, finalmente, medio para comunicar el conocimiento experiencial generado. Dentro de esta última, se han utilizado tres procedimientos que hemos denominado: denotativo autorreferencial, connotativo texto-visual y secuencial.

Palabras clave: imagen fotográfica, comunicación visual, relación intercultural, conocimiento mutuo, foto-elicitación.

\begin{abstract}
This paper presents the results and analysis of one of the objectives of the I+D+I projects approved by the Ministry of Economy and Competitiveness of Spain entitled "Audiovisual mediations in relationships between schools and immigrant families”. It was aimed to find the specific functions that the photographic images have in the relationships of a group of immigrant parents in the school to which their children attend. The data presented correspond to biographical, cultural and visual storytelling started in the classroom by the tutor group for these families, and continued in their personal and social contexts. We concluded that the photographs in the stories had the following functions: source of information, support analysis, reflection and debate, and finally as a means to communicate the experiential knowledge
\end{abstract}

1 Proyecto subvencionado por el Ministerio de Economía y Competitividad, referencia EDU2011-23380. 
generated. In this sense, parents used three methods which we have called: self-referential denotative, connotative text-visual and sequential.

Keywords: photographic image, visual communication, intercultural relationship, mutual understanding, photo-elicitation.

Este artículo contiene parte de los resultados de un proyecto que versa sobre la inclusión y participación democrática de las familias inmigrantes en las instituciones del país de acogida. La escuela tiene un protagonismo importante en estas acciones porque puede servir de puente en las relaciones entre dichos humanos y la comunidad donde viven. En este sentido, el fin de este estudio es conocer qué prácticas educativas, qué discursos institucionales, qué estrategias de relación familias-escuela-comunidad son las mejores para fomentar la participación y el compromiso de padres, madres y alumnado con el proyecto educativo del colegio y de convivencia democrática en el barrio donde este está asentado.

La relación familia-escuela-comunidad, así como la vinculación de los procesos educativos con el contexto escolar, han sido contempladas en diferentes disposiciones legales que definen y orientan el quehacer de la formación institucional (Constitución Española, 1978, arts. 10,19, 27, 39...; LOECE, 1980, arts. 16, 18, 26...; LOGSE, 1990, art. 57; LOPEGCE, 1995, arts. 5 y 6; LOCE, 2002, art. 88.2; LOE, 2007, arts. 1.h, 91.c, 118. 1, 3 y 4...), siendo muy clarificador, por ejemplo, el espíritu de las mismas recogido en el artículo 118.4 de la LOE: “A fin de hacer efectiva la corresponsabilidad entre el profesorado y las familias en la educación de sus hijos, las Administraciones educativas adoptarán medidas que promuevan e incentiven la colaboración efectiva entre la familia y la escuela”.

De esta forma, el contenido del presente texto recoge sólo parte de los resultados del proyecto de investigación que aborda dos temas relacionados; uno, la comunicación entre la escuela y familias inmigrantes; otro, el papel de los equipos y lenguajes audiovisuales en dichas relaciones. Ambos pretenden aportar un conocimiento que, además de reducir la tasa de fracaso escolar de este alumnado extranjero, ayude a mejorar la vida de sus padres y madres en la comunidad y país de acogida. Concretamente, en este artículo presentamos resultados sobre la función de la imagen visual en la relación de un grupo de familias entre sí y con la profesora tutora del colegio al que van sus hijos e hijas. Es decir, ante la temática del proyecto, en este artículo daremos respuesta a la siguiente cuestión de investigación ¿Qué funciones tienen las imágenes fotográficas en las relaciones que un grupo de padres inmigrantes mantienen entre sí y con la profesora tutora en el colegio al que asisten sus hijos cuando narran historias sobre temas propuestos por ellos?

\section{Marco teórico}

Uno de los elementos sustantivos del anterior interrogante es la relación o interacción entre un grupo de familias inmigrantes mediada por el lenguaje fotográfico, además del verbal y textual. En este sentido, uno de los fundamentos de este artículo reside en el enfoque histórico cultural porque, desde el punto de vista del grupo de 
investigación, es el modelo que ayuda a comprender el desarrollo de las personas a través de la relación que existe entre ellas. Este planteamiento fue iniciado por Vygotski (1979), aportando que la mente se desarrolla cuando se ejercita, cuando entra en funcionamiento; y esto sucede cuando los seres humanos se relacionan con su contexto físico y social. Esta autor observó que esta relación era mediada, bien por herramientas físicas como el arado o la azada (en la actividad agrícola de su tiempo, por ejemplo) o simbólicas como los lenguajes verbal, textual o fotográfico. Posteriormente, Luria (1980) explicó cómo la mente de las personas se estructura y funciona atendiendo al procesamiento de los elementos de esos sistemas de representación, y Leontiev (1983) añadió que los significados que tienen las herramientas de mediación atienden en buena medida a las funciones que ocupan en sistemas de actividad organizados socialmente.

Los elementos conceptuales precedentes permiten entender cómo aprendemos o incorporamos los significados que tienen los objetos, las relaciones, etcétera, de una cultura concreta. Ante el propósito de este artículo, vamos a exponer brevemente cómo explicó Vygotski (1979) la incorporación o aprendizaje que hacen las personas de los significados de los elementos culturales cuando se relacionan con otras dentro de lo que denominó zona de desarrollo próximo (ZDP). Este proceso tiene dos fases o momentos; la primera de ellas comprende las relaciones interpersonales 0 interpsicológicas, donde las personas se relacionan unas con otras y donde, en ciertos momentos, una o unas de ellas orientan su actividad física o mental orientada por el lenguaje de otra persona más desarrollada en ese campo de acción o pensamiento (ZDP). Según este autor, en esta primera etapa, la interacción realizada convierte el lenguaje externo en interno o lenguaje de pensamiento para cada uno de los participantes en esas relaciones sociales; es decir, el pensamiento de un ser humano es actividad física y social interiorizada. La segunda fase, está configurada por las relaciones intrapersonales o intrapsicológicas que mantiene cada persona consigo misma utilizando el lenguaje del pensamiento configurado en la etapa anterior para orientar de forma autónoma sus acciones.

En la actualidad, este enfoque ha sido completado por Engeströn (1987) con su teoría de la actividad, y por la perspectiva del aprendizaje situado de Brown y Duguid (2000), Streibel (1989), Bruner (1997) y Wertsch (1999), entre otros. Las aportaciones de estos dos últimos autores cobra especial interés en este texto, porque la narración de historias se considera una herramienta de mediación entre humanos, un proceso de construcción social de significados, un espacio simbólico de intersubjetividad, donde se comparten miradas, creencias, manifestaciones, pensamientos, emociones,... para lograr el conocimiento del Otro/a y, consecuentemente, la comprensión mutua de participantes diferentes vinculados a unos contextos y situaciones concretas.

Con este marco teórico de referencia, hemos revisado estudios relacionados al binomio imagen visual y familias en un contexto escolar. Encontramos estudios donde los medios tecnológicos han tenido un interés especial en el análisis de la comunicación entre escuelas y familias (Diez y Terrón, 2006; Martínez, Rodríguez y Gimeno, 2010). Entre sus conclusiones figura la presencia de herramientas culturales para concretar la reunión de los padres con el profesorado, siendo la agenda escolar y 
las anotaciones textuales las más frecuentes, y el teléfono y el correo electrónico los menos utilizadas. También, se han realizado investigaciones sobre el valor de la narración audiovisual de historias en la relación entre alumnos diversos culturalmente (Bautista, Rayón y De las Heras, 2012) y para desarrollar competencias creativas y digitales en futuros maestros (Villalustre y Del Moral, 2014).

En los anteriores estudios percibimos una atención menor a la indagación sobre la relación entre familias inmigrantes que, además de ser el objetivo de este artículo, es la base de la educación intercultural, fundamentada en el principio de la interacción con el Otro distinto, porque cuando nos relacionamos nos conocemos. En este sentido, consideramos que una de las aportaciones de este texto es presentar y discutir datos sobre el papel y naturaleza de las representaciones fotográficas en el conocimiento y entendimiento mutuo cuando son usadas por padres y madres diferentes culturalmente para narrar historias propias.

Ahora bien, ¿en qué fundamentamos la estrategia didáctica que proponemos basada en la narración de relatos utilizando la fotografía como sistema básico de comunicación? Es decir, cuando algún padre o madre cuenta una historia con imágenes a otros padres y madres diferentes por su origen cultural ¿qué función asignan a la fotografía en ese proceso de conocimiento mutuo? Atendiendo a las aportaciones de la indagación narrativa visual (Bach, 2007; Caine, 2010), pensamos que usando la imagen visual proporcionamos posibilidades de intercambio y comunicación a los participantes; es decir, oportunidades para explicitar sus intenciones y el significado de lo vivido en un lugar y en un momento concreto. Uno de los principios que fundamenta esta idea es considerar la experiencia vivida como una historia y, como tal, puede ser contada con imágenes (Bach, 2007). Tal consideración permite conocer una realidad desde el punto de vista de los participantes que la viven o han vivido. En este sentido, la indagación narrativa con fotografías permite a padres y profesorado de un colegio analizar sus propias vidas a la vez de conocer cómo son las de otros.

Metodológicamente, una manera de concretar estos procesos de indagación visual es mediante las denominadas situaciones de foto-elicitación (Clark-Ibáñez, 2007) o de foto-voz (Wang, Yi, Zhan and Carovano ,1998); en ellas se pide a los informantes que hagan sus propias fotos, o elijan algunas de una fuente de datos (álbumes) para, posteriormente, proyectarlas $\mathrm{y}$, a modo de recuerdos, fomentar la manifestación de las experiencias de vida, significados o emociones de quienes las realizaron o eligieron. $\mathrm{Su}$ valor reside en que

"la proyección de una fotografía hecha por un humano sobre un evento que ha vivido, permite hacer visible sus intenciones, creencias, afectos $\mathrm{y}$ pensamientos, así como poder analizarla, comentarla, estudiarla y debatirla hasta llegar a comprender los significados y sentimientos que pretendía transmitir” (Bautista, 2013, p. 73).

Pues bien, en este artículo nos centraremos en las funciones que los padres y madres participantes asignan a la fotografía en esas sesiones narrativas orientadas al conocimiento mutuo. 


\section{Objetivo de investigación}

Ante lo planteado en los apartados previos, en este artículo abordaremos el siguiente objetivo de investigación: Conocer las funciones que tienen las imágenes fotográficas en la relación que mantienen entre sí un grupo de padres inmigrantes y con la profesora tutora del colegio al que asisten sus hijos cuando narran historias sobre temas elegidos por ellos.

\section{Metodología}

Por la naturaleza experiencial de los datos necesarios para responder al anterior objetivo, el diseño de esta investigación se centró en un estudio de caso, concretado en las familias del alumnado de un aula del colegio al que asisten sus hijos y en su profesora tutora (Stake, 1989). Metodológicamente, hemos contemplado dos situaciones especiales para conocer la función de la fotografía en el conocimiento del Otro. Fueron dos espacios que, a modo de estrategia didáctica, pretendieron hacer visibles y conjugar las intenciones de las familias al contar algún episodio de sus vidas y las interpretaciones que hacían el resto del grupo. Uno de ellos, se refiere a los procesos de discusión sobre la construcción de las historias verbo-visuales (elección de contenidos, producción o selección de imágenes y fragmentos musicales). Para ello, solicitamos a los padres que, una vez que eligieron el tema a narrar, hiciesen o buscasen fotografías sobre el mismo; por ejemplo, sobre su casa y su barrio, sobre su país de procedencia, etcétera. Seguidamente, a petición de la profesora-tutora del grupo de sus hijos y de los miembros del equipo de investigación, estas familias tenían que registrar fotográficamente lo que deseaban contar, señalando aquello que les producía más emoción o angustia, más alegría o tristeza, etcétera.

Posteriormente, en la segunda fase, propiamente de foto-elicitación, debían llevar esas imágenes a las reuniones grupales que celebramos cada dos semanas en el colegio, para proyectarlas al resto de padres, y comunicar el porqué de las mismas. En esta segunda situación, pudieron comentar todos juntos las fotografías que realizaron o buscaron hasta llegar a comprender su contenido. De esta forma, hubo contraste de pareceres entre los participantes (padres y madres, tutora y miembros del grupo de investigación); es decir, metodológicamente, para obtener información que nos permitiese responder al objetivo señalado, los miembros del grupo de investigación diseñamos las dos situaciones coordinadas en un proceso de foto-elicitación.

\section{Sobre la recogida de información}

Las observaciones y registros de las anteriores situaciones de relación intercultural se hicieron siguiendo las aportaciones de la Etnografía de la Comunicación Cultural (Hymes, 1974; Carbaugh, 1990; Gudykunst y Shapiro, 1996, entre otros) y de la Antropología Audiovisual (Grau, 2002; Pink, 2007; Banks, 2010;...). Triangulamos la información utilizando tres tipos de datos que, ante la naturaleza de los procesos estudiados, fueron mediante: 
- Observación sistemática de los procesos de relación, derivada del rol de observadores participantes que teníamos los miembros del equipo de investigación en las sesiones de foto-elicitación.

- Grabaciones en audio de los procesos de discusión ante las fotografías proyectadas.

- Entrevistas puntuales (individuales y grupales), para precisar el contenido de las comunicaciones interculturales y de las relaciones de las familias con el colegio, para indagar sobre el efecto de las narraciones audiovisuales en el conocimiento del resto de familias.

\section{Sobre el análisis de los datos registrados}

El tema de investigación versa sobre los beneficios de la narración fotográfica en las interacciones entre padres, así como los efectos en su desarrollo personal y social. Con este fin revisamos la literatura sobre el análisis de datos visuales. Encontramos algunos trabajos que contemplen procedimientos directos de análisis de la imagen en las relaciones humanas (Denzin, 1989; Van Dijk, 2000; Flick, 2004; Banks, 2010). Por ejemplo, Van Dijk (2000) manifestó que, en muchas ocasiones, no se contemplan las imágenes que motivan o subyacen en las relaciones discursivas.

Teniendo presente la anterior consideración, el análisis de la información verbovisual lo hicimos de forma manual contemplando la descripción (fenomenológica) y la interpretación (hermenéutica) de los tres tipos de datos señalados en el punto anterior. En el proceso de análisis tuvimos presente las tres fases seguidas por Wetherell y Potter (1992) en sus estudios. El proceso seguido fue:

- Fase preliminar de criba de unidades discursivas verbo-visuales relacionadas con los distintos papeles otorgados a la imagen fotográfica.

- Fase intermedia de análisis de las unidades discursivas audiovisuales hasta llegar a repertorios interpretativos, o aproximación de usos parecidos, o de la misma naturaleza, de la fotografía.

- Fase final o combinación de categorías u organización de repertorios interpretativos como un TODO, o unidad en el proceso de relación intercultural.

\section{Introducción en el colegio, familias y número de sesiones desarrolladas}

En octubre del año 2011 presentamos el proyecto al equipo directivo y al claustro de profesores del Colegio de Educación Infantil y Primaria (CEIP) Jaime Vera de Madrid (España), centro que tiene un 89\% de alumnado inmigrante. Una vez aceptada su participación, la profesora-tutora de un grupo de $4^{\circ}$ curso de Educación Primaria (niños y niñas de 10 años) nos invitó y puso en comunicación con las 19 familias de su alumnado en una reunión para, según figuraba en la convocatoria, “conocernos mejor 
contando historias con fotografías y vídeos de nuestro barrio en Madrid, familia, país de origen, etcétera”. A esta cita, celebrada en el colegio, asistieron 14 padres y madres. Desde entonces y hasta final de año 2013, mantuvieron su continuidad en las reuniones quincenales 3 familias de República Dominicana, 1 de Bangladesh, 1 de Perú, 1 de Ecuador y 1 de España; y se incorporó 1 de Marruecos en septiembre de 2012. Las reuniones tuvieron lugar en el colegio, cuando las clases habían finalizado, normalmente fueron los viernes, de 16 a 18 horas. En todas ellas asistieron al menos 4 familias, que fue el número mínimo que acordamos para poder desarrollarlas. En total se celebraron 29 sesiones, 13 en el curso 2011-12, y 19 entre octubre de 2012 a diciembre de 2013. Los padres y madres dieron su consentimiento para utilizar todas las fotografías que se hiciesen, incluidas las que estuviesen presentes sus hijos menores de edad. Evidentemente, manifestamos nuestro compromiso de usarlas únicamente con fines académicos.

\section{Presentación y discusión de resultados}

En los procesos de narración que emergieron en las sesiones de foto-elicitación, la fotografía (y su lenguaje) fue una herramienta simbólica de representación soportada en medios tecnológicos (la cámara fotográfica) que, como documentaremos seguidamente, ha tenido tres funciones: registrar y evocar información, soportar análisis y discusiones sobre la misma y, finalmente, representar y comunicar las ideas y afectos que conformaron las narraciones generadas.

\section{a) Uso de la fotografía para registrar y evocar información}

Como en este estudio participaron tres familias procedentes de la República Dominicana, uno de los miembros del grupo, proyectó la fotografía $\mathrm{n}^{\circ} 1$ en la reunión del día 11 de mayo de 2012 porque, entre otras, estaban presentes estas madres y padres. Inmediatamente, emergió el siguiente proceso discursivo:

- Madre 1 República Dominicana (Madre 1 RD): Ya sé, esta fotografía es del día 26 de febrero de 2012, donde celebramos en Madrid la fiesta de carnaval que en ese mismo día tenía lugar en mi país, Republica Dominicana. La foto, es de la calle Bravo Murillo, se ve a muchas familias dominicanas, vestidas con el traje típico de mi país, participando en la fiesta. 


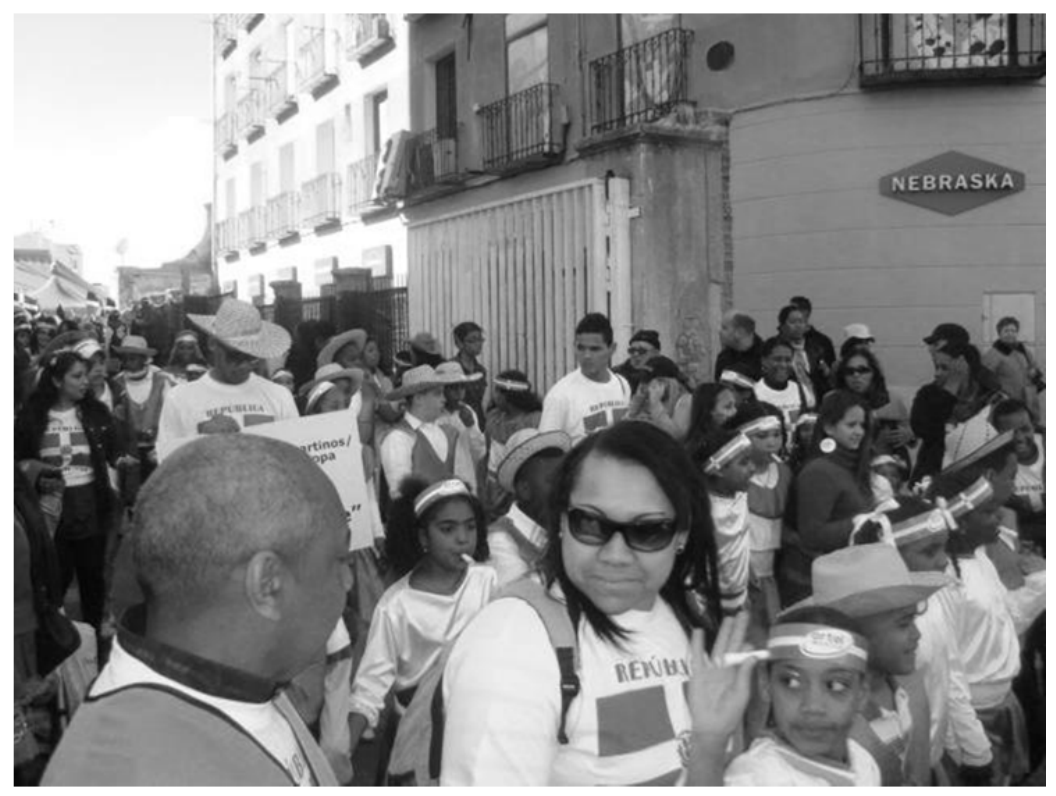

Fotografía 1. Carnaval de la República Dominicana en Madrid. Propiedad: Investigadores.

- Madre 2 RD: Sí, yo también estuve ese día. A las 6 de la tarde la calle de Bravo Murillo estaba cortada al tráfico para que las carrozas y las comparsas desfilaran desde Cuatro Caminos hasta la plaza de la Remonta.

- Madre 3RD: Sí, lo que no se puede fotografiar, aunque se adivina, porque casi se puede oír viendo la foto, es el ritmo de merengue y reggaetón que había en el ambiente.

Investigador: ¿cuánto duró esa celebración?

- Madre 2 RD: Hasta las 8. Todos los años termina en la plaza de la Remonta, cuando la concejala del distrito de Tetuán y representantes de la comunidad dominicana dan una charla.

- Madre 3 RD: Sí, pero este año se suspendieron los discursos, porque hubo una explosión de un petardo potente, y se produjo un revuelo entre nosotros, porque pensamos que era un disparo de una reyerta entre bandas rivales.

Estos comentarios verbales demuestran que la fotografía además de mostrar información física sobre personas y objetos visibles de la realidad que se pueden describir, también tiene la función de recordar sensaciones como la música, y el colorido, y acontecimientos como el desfile de carrozas o la estampida producida por un petardo. Desde un punto de vista del enfoque histórico-cultural, la fotografía ha sido una herramienta importante en las relaciones interpsicológicas pues, con esa función de 
registro y representación, hizo posible la relación entre ese grupo de padres y madres inmigrantes.

Pero, también, hubo otro tipo de evocaciones como la siguiente:

- Madre 1 RD: La fotografía me trae buenos recuerdos. Al verla, mi memoria vuela a cuando era pequeña y vivía allí; y estaba en la fiesta como esos niños de la fotografía. Lo siento, no puedo evitar que mis ojos se llenen de lágrimas”.

Esta manifestación muestra que, además de informar de elementos y relaciones físicas perceptibles, la fotografía también ha sido fuente de información sobre sentimientos y afectos no visibles, porque tuvo la función añadida de evocar recuerdos emotivos. Observamos que, en este caso, la imagen ha facilitado las relaciones intrapersonales, porque ha llevado a un proceso de búsqueda e indagación de esta madre en sí misma hasta remontarse a su infancia.

Contemplando los anteriores procesos interactivos, se aprecia que la fotografía en todos ellos tiene en común informar, bien sobre la materialidad física que soporta su contenido (favoreciendo las relaciones interpersonales), o bien sobre lo tácito e íntimo de los participantes cuya evocación fue facilitada por la imagen (como resultado de las relaciones intrapersonales generadas).

b) Uso de la fotografía para soportar análisis y discusiones sobre el contenido de la misma

Atendiendo al tema de narración acordado en una sesión por el grupo participante sobre "la vida en familia", el padre marroquí que se incorporó en septiembre de 2012 llevó la fotografía $\mathrm{n}^{\circ} 2$ a la reunión del 25 enero de 2013 para mostrar una escena típica familiar. Una vez proyectada se produjo el siguiente diálogo: 


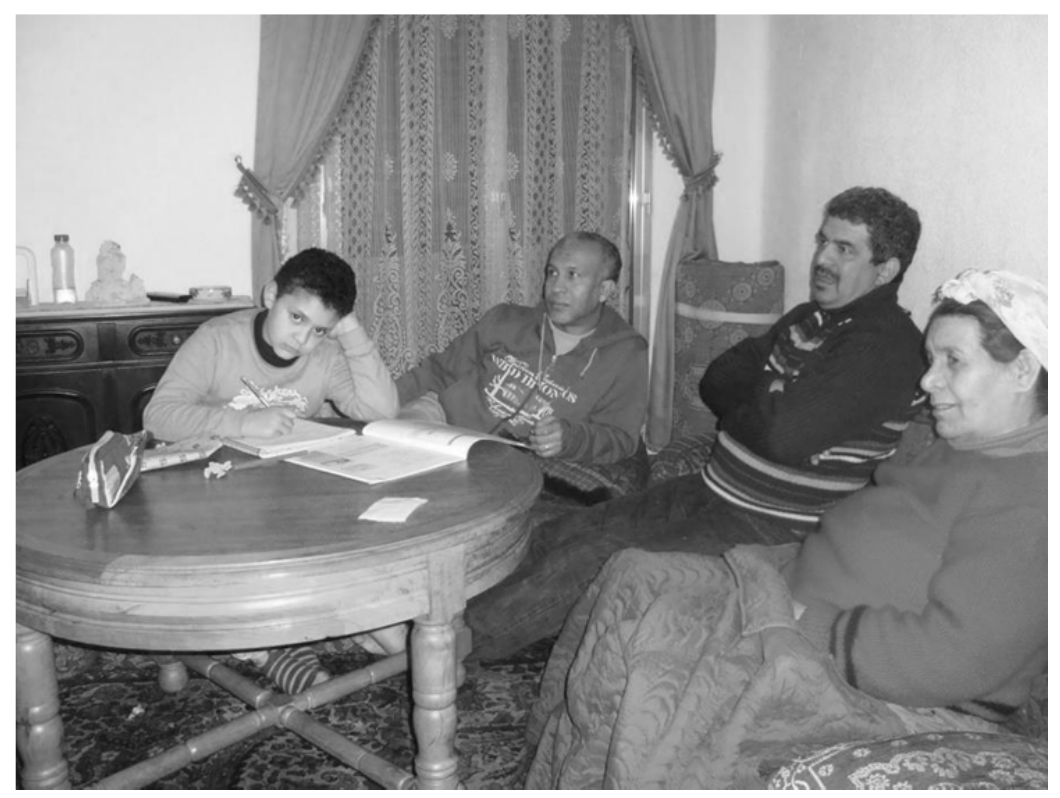

Fotografía 2. Escena familiar.

Propiedad: Investigador (donada por el autor).

- $\quad$ Padre (P). Esta es una escena familiar en casa, están mis padres y mi hijo haciendo los deberes.

- Miembro 1 del Grupo (MG1). Hay como diferentes miradas, la tuya y la de tus padres es hacia la izquierda, y la de tu hijo hacia la cámara. ¿Adónde mirabais?

- P: Estábamos viendo la TV, a mi hijo no le importa; además muchas veces pregunta cosas sobre las imágenes o programas que vemos.

- MG1. ¿Hay algún programa de televisión interesante por las tardes? ¿qué cadena teníais puesta? Se os ve sonrientes. Seguro que no eran dibujos animados.

- P: Es un canal de televisión árabe, se llama Alahacería, que vemos a través de una antena parabólica. Además de noticias sobre Marruecos, presentan documentales sobre fiestas y gastronomía de mi país, Marruecos. Lo ponemos como parte de la educación de mis hijos; para que conozcan lo que pasa en el país donde nacimos y donde tenemos familia.

- M.G1. Bueno, ahora entiendo mejor lo de la televisión y vuestras caras de atención.

- MG2: A mí me parece bien que veáis una cadena de televisión de vuestro país; además, creo que es una decisión muy buena en la educación de vuestros hijos, pero lo que no entiendo es por qué la veis cuando tu hijo está haciendo los deberes del colegio.

- P: Porque no hay otro lugar en la casa donde pueda hacer los deberes, porque en las habitaciones están las camas y no hay espacio para una mesa. En muchas ocasiones cuando hace los deberes la televisión está apagada, pero a veces, 
coinciden la emisión de una información importante y la urgencia de hacer unos ejercicios para el colegio. Uno de esos momentos fue el que recoge la fotografía, que hizo mi mujer.

- MG3: Es verdad. Pero oye, una pregunta ¿por qué tu madre tiene ropa de abrigo?

- P: Porque no había calefacción y, como hacía frío por la noche, nos abrigamos.

(Fragmento de la reunión del 25 de enero de 2013).

El anterior fragmento de debate ilustra el uso de la imagen para analizar la realidad captada fotográficamente de un instante de la vida de una familia, así como las sensaciones que estaban experimentando los protagonistas de la misma. La imagen contiene o soporta elementos cuya percepción y análisis lleva a construir significados sobre el sentido de la realidad captada. Lo distintivo de este uso frente a la anterior función de registro de datos, es que va más allá de la transmisión de la información de un instante de vida, y se centra en ser soporte de extrañamientos y cuestionamientos por parte de los participantes en las sesiones de foto-elicitación (por ejemplo ¿̇adónde mirabais? ¿por qué llevaban ropa de abrigo? etcétera) y, así, poder entender su contenido, en este caso, la manera de vivir esta familia marroquí.

En las entrevistas puntuales que realizamos a los padres después de estas sesiones, tres de estas familias, cada unadesde sus referentes interpretativos, manifestaron que la fotografía, de alguna forma, fijaba o "mantenía presente el tema sobre el que hablar todos los padres", es decir, la imagen daba vida a las relaciones interpresonales; en este sentido, su valor se aprecia en la necesidad de mantener presentes las ideas y argumentos de la discusión sobre su contenido, para analizarlo, cuestionarlo y, consecuentemente, construirlo y elaborarlo mejor.

La integración de los puntos de vista de los participantes en los procesos de discusión, proporcionó la emergencia de una comprensión del contenido narrado y del sistema de creencias y referentes interpretativos de los protagonistas de la fotografía que era objeto de debate. De esta forma, como apunta Rose (2007), la combinación de intenciones del autor en una situación de vida con las interpretaciones hecha por otros sobre la misma evitó una recontextualización, es decir, en este caso, que los referentes socioculturales de esta familia marroquí fuesen modificados y transformados.

Esta función de la fotografía como soporte y análisis de datos emerge cuando el grupo discute sobre su contenido, cuando, más que describir, se pregunta y debate sobre el porqué y el sentido de los elementos de esa imagen. Por lo tanto, esta función de la fotografía depende de los participantes, porque es demandada por ellos cuando la usan con la finalidad de analizar y estudiar la realidad que representa e informa en su contenido. Desde el enfoque histórico cultural, observamos que este papel de la imagen fija favorece tanto las relaciones inter como intrapersonales porque, ante una pregunta, se obliga al padre o madre cuestionada que ponga en funcionamiento su pensamiento, o relación intrapsicológica, para, con el resultado del mismo, poder responder al contenido de la pregunta o extrañamiento y, de esta forma, continuar con las interacciones interpersonales que configuran su conocimiento mutuo. 


\section{c) Uso de la fotografía para representar y comunicar las ideas y afectos que conforman las narraciones}

Finalmente, en algunas sesiones de trabajo con el grupo de padres y madres, o más concretamente, en algunos de esos momentos, observamos que varios de los participantes pretendían comunicar o presentar parte o uno de los episodios del contenido de la historia que estaban construyendo y era objeto de narración. Es decir, mostraban cómo comunicaban una idea o experiencia utilizando la fotografía. Una de las formas o estrategias más frecuentes fue el caso de la madre de Ecuador que usó la fotografía $\mathrm{n}^{\circ} 3$ para comunicar a los familiares que tenía en su país cómo era el colegio donde iban sus hijos:

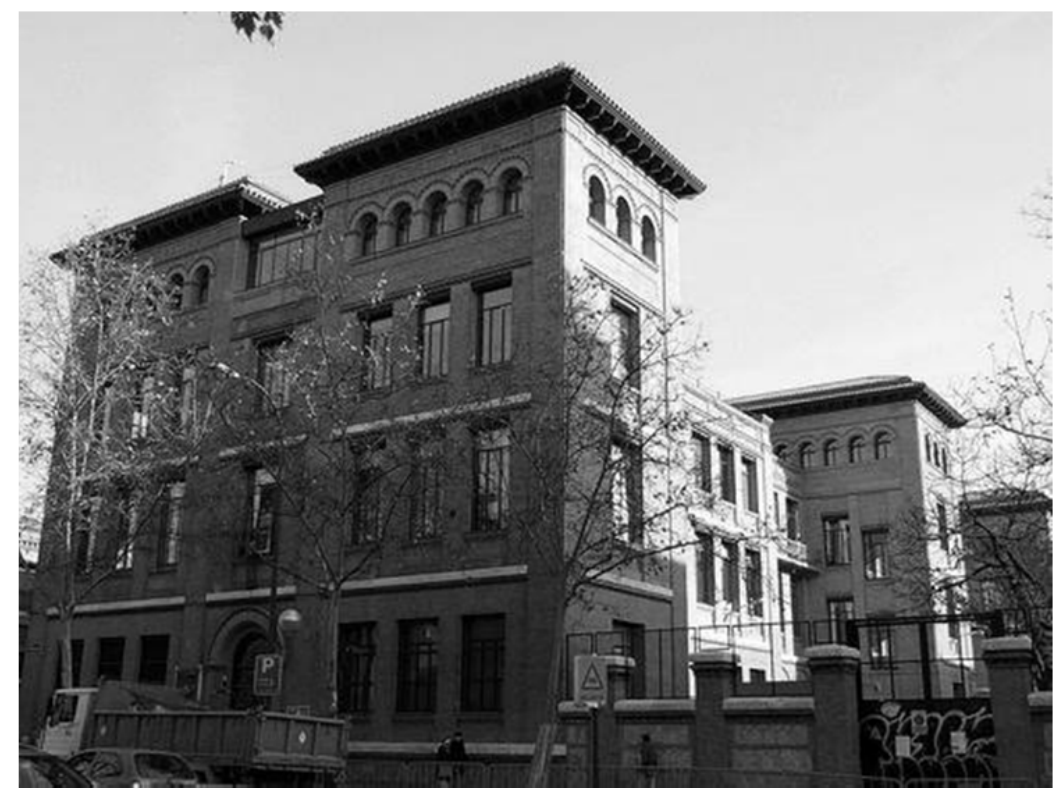

Fotografía 3.

Proporcionada por Rocío.

\section{En la reunión comentó:}

- Madre de Ecuador: "He tomado esta foto porque en ella se ve bien la fachada principal y los otros edificios interiores del colegio. A mí, esta fotografía me gusta mucho porque se ve lo bonito que es el colegio; claro también influye que hace sol y se ve mejor"

(Fragmento de la reunión del 18 de octubre de 2013).

Observamos que esta madre aplicó la dimensión denotativa de la imagen, en el sentido que le dio Le Guern (1985), porque la utilizó para comunicar la existencia de un contenido sin necesidad de otros referentes de significado para poderlo comprender; concretamente, la empleó para decir cómo es una realidad física (fachada y edificios de 
un colegio, en este caso) a otras personas no presentes en ese lugar y en el momento de captar esa imagen. En este sentido, en el grupo acordamos hablar de ella como una estrategia "denotativa o autoreferencial".

Una segunda estrategia que estas familias usaron para comunicar una idea mediante fotografías se observó, por ejemplo, cuando el padre de Bangladesh utilizó la fotografía $\mathrm{n}^{\circ} 4$ dentro de la narración acordada por el grupo titulada "El colegio desde la calle". Como parte de la historia que deseaba comunicar basada en su experiencia personal, mostró esa imagen con el siguiente pie de foto: "Encuentro entre países”.

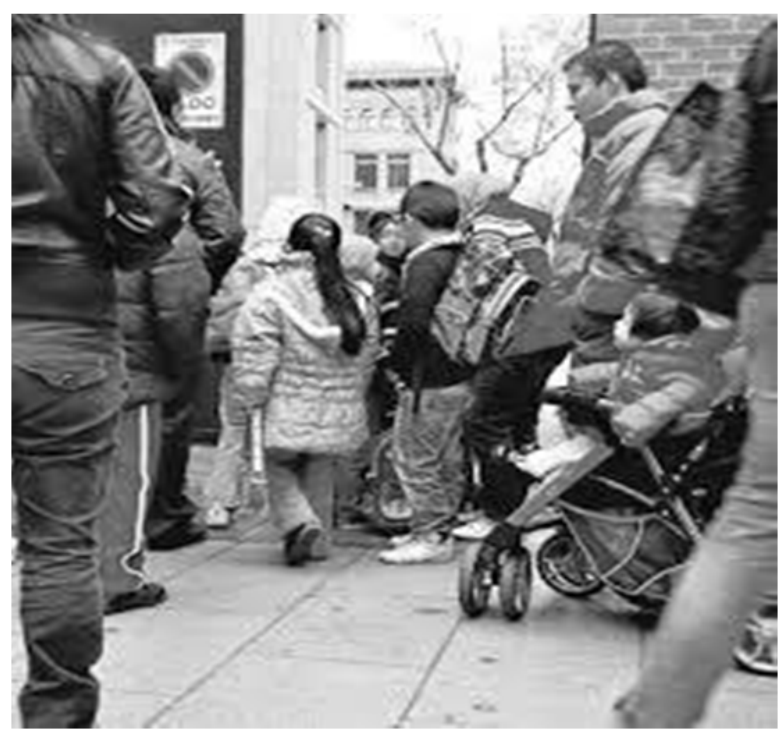

Fotografía 4.

Autor: Said (proporcionada al grupo).

Al presentarla al grupo, manifestó:

"Said: Entre las cosas que voy a contar en mi historia de cómo veo el colegio, es lo que he pensado muchos días a las 9 (de la mañana) y a la salida a las 4 de la tarde, cuando traigo a mi hija y cuando la busco para llevarla a casa. Al ver a tantos niños y padres en la puerta, y tan diferentes por sus países, pienso que en estos momentos la puerta del colegio es un encuentro entre países, es como si se saludara mi país, Bangladesh, con Ecuador, con Perú, con Marruecos,... y con España” (Fragmento de la grabación de la reunión del día 15 de noviembre de 2013).

Esta segunda estrategia, respecto a la anterior, incorpora un texto al pie de la fotografía para comunicar una idea elaborada por un padre. El texto tiene la función de 
connotar o contextualizar, a modo de marco interpretativo, el significado que se quiere transmitir con esa imagen. O, de otra forma, el texto tiene la función de concretar o acotar la polisemia que tiene la fotografía. Atendiendo al sentido que dio Le Guern (1985) a la dimensión connotativa, hemos denominado a esta estrategia comunicativa como “connotativa texto-visual”. La sensación que ha producido esta combinación en el grupo de padres e investigadores es que el texto y la imagen son dos sistemas de representación que se apoyan mutuamente para potenciar el significado que se quiere comunicar, siendo más expansivo de esta forma que si se hubiese transmitido utilizando cada uno de ellos por separado.

Para terminar, hemos observado un tercer procedimiento de utilización de la fotografía por los padres para comunicar algún fragmento o episodio de la historia que es objeto de narración. Lo hemos denominado "secuencial” y se basa en la disposición de varias fotos según un principio de ordenación, tal como el espacio, el tiempo, los personajes representados, etcétera. A modo de ilustración presentamos la secuencia de las fotografías números 5, 6 y 7, que utilizó Mar, una madre española, para mostrar distintas fachadas y detalles de los edificios del colegio dentro de la narración "El colegio desde la calle”

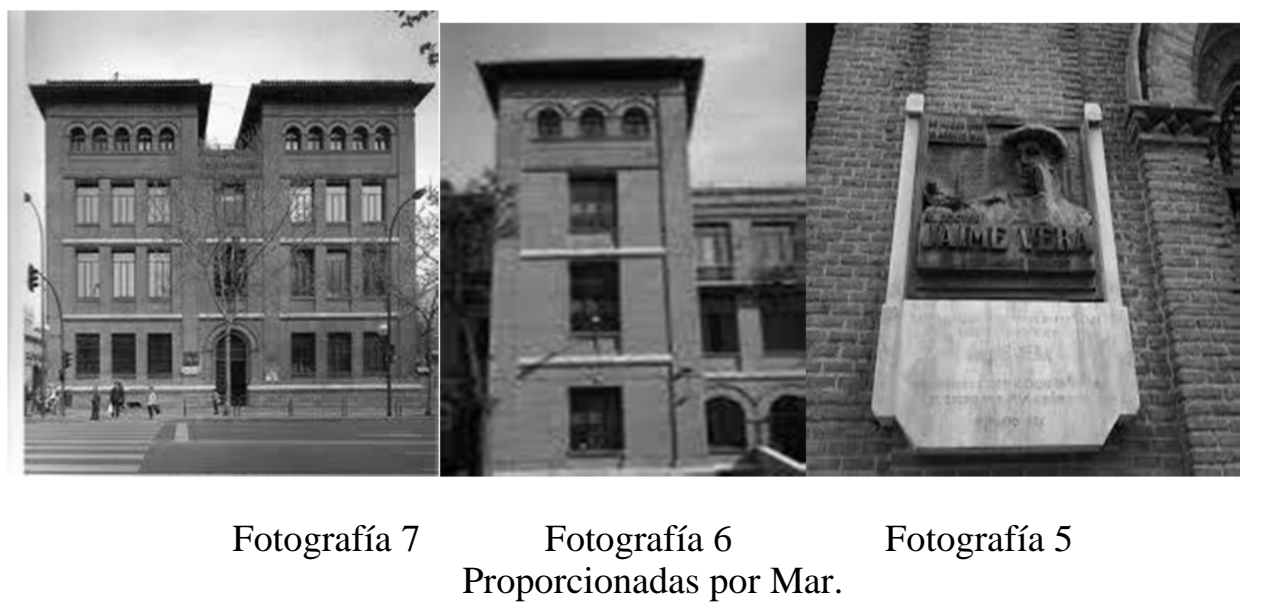

La presentación se hizo así:

- Mar: Para contar cómo veo el colegio desde la calle, he empezado utilizando estas tres fotografías para decir cómo he ido viendo el colegio. La verdad es que la primera vez que reparé en él y pensé traer a mi hijo e hija fue viendo la placa que hay en la entrada donde se dice quién fue Jaime Vera (foto $n^{\circ} 5$ ). Esta idea me creó curiosidad y empecé a mirar más detalles de los edificios como las ventanas... (foto $n^{\circ} 6$ ). $Y$, otro día, me dije, hoy voy a ir al colegio por la acera de enfrente, no por la de siempre; y entonces vi su fachada principal (foto $\mathrm{n}^{\circ} 7$ ) y me dije, la verdad es que es bonito.

- Investigador: Una curiosidad ¿por qué presentas las fotografías en este orden? Es decir, desde una visión de detalle a una general. 
- Mar: La verdad es porque lo he ido viendo así, y creo que quien no lo conozca le producirá suspense ir poco a poco descubriendo cómo es.”

(Fragmento de la reunión del día 8 de noviembre de 2013)

Esta estrategia secuencial usada por Mar comunica fotográficamente a través del descubrimiento del contenido a narrar. Evidentemente, el principio de ordenación también podía haber sido atendiendo al factor tiempo, es decir, presentando la fachada del colegio en diferentes momentos; por ejemplo, cada 10 años, empezando desde principios de siglo XX, para entender cómo ha sido su evolución. Los fundamentos de este procedimiento son los mismos del "denotativo", pero repetido según un principio de secuenciación.

Contemplando estas tres estrategias desde el enfoque histórico cultural, percibimos que, si bien todas tienen el fin informar o nutrir de contenido las relaciones interpersonales, tienen más relevancia o peso las intrapersonales generadas porque dan como resultado la representación mediante fotografías de las ideas, creencias o afectos que han de ser comunicadas.

\section{Conclusiones}

En las sesiones de narración con un grupo de padres inmigrantes en el colegio al que asisten sus hijos, la fotografía ha sido usada para tres funciones: registrar y evocar información que será el contenido del relato a desarrollar, analizar y discutir sobre la misma y, finalmente, representar y comunicar la historia que es objeto de narración. Hemos observado que estas funciones fueron demandadas por los usuarios, no son funciones que figurasen en el catálogo de características o elementos recogidos en el manual de instrucciones de una cámara fotográfica. En este sentido, podemos aportar que los padres y madres participantes en este estudio, al ubicarlos en contextos de narración de historias usando el lenguaje fotográfico mediante una cámara de fotos, han ido más allá del significado clásico de esta herramienta que es la de captar e inmortalizar un momento, pues también lo han usado para analizar y comunicar ideas y emociones. Por lo tanto, han reasignado, nuevos significados/funciones a la cámara fotográfica y, consecuentemente, al lenguaje de la imagen fija. De esta forma, en una misma sesión de foto-elicitación, se han podido alternar las funciones de registro de información y de soporte de análisis de la misma atendiendo al uso que hacían de la fotografía los participantes, bien para describir y proporcionar datos de una realidad, bien para analizarla mediante interrogantes o extrañamientos de su contenido.

Dentro de la tercera de las funciones demandadas a la fotografía, hemos comprobado cómo han usado tres estrategias o formas de comunicar una narración o parte de ella. Las hemos denominado: denotativa autoreferencial, connotativa textovisual y secuencial. Este grupo de padres y madres ha sabido ensayar y modificar el orden o disposición de las fotografías dentro del relato para conferir una idea o emoción determinada, de tal modo, que el significado que podía tener una imagen aislada se agregaba o modificaba el que tenía la anterior o la posterior de la secuencia 
que diseñaban, proporcionando nuevos sentidos a la historia narrada, al sentimiento o emoción que ellos y ellas pretendían dar sobre el colegio, sobre su país de origen, etcétera.

Observando cada una de estas tres funciones desde el enfoque histórico cultural, percibimos que cada una de ellas ha contribuido a que la fotografía sea una herramienta importante de mediación en el conocimiento mutuo y desarrollo de grupos de personas en general, y de las familias de inmigrantes en nuestro caso, porque ha favorecido, en mayor o menor medida, tanto las relaciones inter como intrapersonales que nutren sus procesos mentales.

Para finalizar, hemos de manifestar en el contexto del proyecto de investigación, que las anteriores conclusiones muestran cómo la narración fotográfica de historias proporciona espacios y momentos de quietud y tranquilidad, suscita situaciones importantes y relevantes de discusión y conocimiento mutuo que, poco a poco, están llevando a los padres y madres participantes a un entendimiento y comprensión mayor entre ellos, así como a mejorar su relación con la escuela.

\section{Referencias bibliográficas}

BACH, H. (2007). Composing a Visual Narrative Inquiry. In Handbook of Narrative Inquiry. Mapping a Methodology, ed. D.J. Clandinin, 280-307. London: SAGE.

BANKS, M. (2010). Los datos visuales en Investigación Cualitativa. Madrid: Editorial Morata.

BAUTISTA, A. (2013). La indagación narrativa visual en la práctica educativa. Educación y Futuro. 29, pp. 69-80.

BAUTISTA, A.; RAYÓN, L. y DE LAS HERAS, A. (2012). Valor de los registros audiovisuales en Educación Intercultural. Comunicar. Revista Científica Iberoamericana de Comunicación y Educación. 39, pp. 169-176.

http://dx.doi.org/10.3916/C39-2012-0307

BROWN, J.S. \& DUGUID, P. (2000). The social life of information. Cambridge, MA: Harvard Business School.

BRUNER, J. (1997). La educación, una puerta a la cultura. Madrid: Visor.

CAINE, V. (2010). Visualizing community : understanding narrative inquiry as action research. Educational Action Research, 18(4), 481-496.

http://dx.doi.org/10.1080/09650792.2012.697405

CARBAUGH, D. (comp.) (1990). Cultural Communications and Intercultural Contact. Hillsdale, NJ.: Lawrence Erlbaum. 
CLARK-IBAÑEZ, M. (2007). "Inter-City Children in Sharper Focus (sobre enfoque de niños marginados). Sociology of Childhood and Photo Elicitation Interviews”. (pp. 167-196). Cap. 7. En Stanczak, Gr. C. Visual Research Methods. CA: Sage.

CONSTITUCIÓN ESPAÑOLA (1978). En Boletín Oficial del Estado número 311, páginas 29313 a 29424.

DENZIN, N.K. (1989). Interpretative interactionism. Londres: Sage.

DIEZ, E.-J.; y TERRÓN, E. (2006). Romper las barreras entre la familia y la escuela. Experiencia de investigación-acción en los centros escolares para promover la relación con las familias. Cultura y Educación, 18 (3-4), 283-294.

ENGESTRÖM. Y. (1987). Learning by expanding. An activity theoretical approach of developmental research. Helsinki: Orienta-Konsultit.

FLICK, U. (2004). Introducción a la investigación cualitativa. Madrid: Morata.

GRAU, J. (2002). Antropología audiovisual. Barcelona: Ediciones bellaterra.

GUDYKUNST, W.B. \& SHAPIRO, R. (1996). Communication in everyday interpersonal and intergroup encounters. International Journal of Intercultural Relations, 20(1), 19-45.

LE GUERN, M. (1985). La metáfora y la metonimia. Madrid: Cátedra.

LEONTIEV, A.N. (1983). El desarrollo del psiquismo. Madrid: Akal.

LOCE (2002). Ley Orgánica 10/2002, de 23 de diciembre, de Calidad de la Educación. En Boletín Oficial del Estado número 307, páginas 45188 a 45220.

LOE (2007). Ley Orgánica 2/2006, de 3 de mayo, de Educación. Boletín Oficial del Estado número 106, páginas 17158 a 17207.

LOECE (1980). Ley Orgánica 5/1980, de 19 de junio, por la que se regula el Estatuto de Centros Escolares. Boletín Oficial del Estado número 154, páginas 14633 a 14636.

LOGSE (1990). Ley Orgánica 1/1990, de 3 de octubre de 1990, de Ordenación General del Sistema Educativo. Boletín Oficial del Estado número 238, páginas 28927 a 28942.

LOPEGCE (1995). Ley Orgánica 9/1995, de 20 de noviembre, de la participación, la evaluación y el gobierno de los centros docentes. Boletín Oficial del Estado número 278, páginas 33651 a 33665.

LURIA, A.R. (1980). Los procesos cognitivos. Un análisis socio-histórico. Barcelona: Fontanella.

MARTÍNEZ, R.A.; RODRÍGUEZ, B.; y GIMENO, J.L. (2010). Áreas de cooperación entre los centros docentes y las familias. Estudio de caso. Educatio Siglo XXI, 28(1), 127-156.

PINK, P. (2007). Doing Visual Ethnography. London: Sage. 
ROSE, G. (2007). Visual methodologies. An introduction to the Interpretation of Visual Materials. London: Sage.

STAKE, R.E. (1989). Investigación con estudio de caso. Madrid: Morata.

STREIBEL, M.J. (1989). Diseño instructivo y aprendizaje situado: ¿Es posible un maridaje? Revista de Educación, 289, 215-234.

VAN DIJK, T. (comp.) (2000). El discurso como estructura y proceso. Barcelona: Gedisa.

VILLALUSTRE, L. y DEL MORAL, M.E. (2014). Digital storytelling: una nueva estrategia para narrar historias y adquirir competencias por parte de los futuros maestros. Revista Complutense de Educación, 25(1), 115-132.

http://dx.doi.org/10.5209/rev_RCED.2014.v25.n1.41237

VYGOTSKI, L.S. (1979). El desarrollo de los procesos psicológicos superiores. Barcelona: Crítica.

WANG, M.P., YI, W.K., ZHAN, W.T. \& CAROVANO, K. (1998). Photovoice as a participatory health promotion strategy. Health Promotion International, 13(1), 7586.

WERTSCH, J.V. (1999). La mente en acción. Buenos Aires: Aique.

WETHERELL, M. y POTTER, J. (1992). Mapping the Language of Racism: Discourse and the Legitimation of Exploitation. Chischester: Columbia University Press.

\section{Correspondencia con los autores}

Antonio BAUTISTA GARCIA-VERA

Departamento de Didáctica y Organización Escolar

Facultad de Educación. Universidad Complutense de Madrid.

Rector Royo Villanova, s/n.

28040. Madrid. España.

Tel. (34) 913946170

e-mail: bautista@edu.ucm.es

Ma Rosario LIMÓN MENDIZÁBAL,

Departamento de Teoría e Historia de la Educación.

Facultad de Educación. Universidad Complutense de Madrid.

Rector Royo Villanova, s/n.

28040. Madrid. España.

Tel. (34) 913946197

e-mail: mrlimonm@edu.ucm.es 
Pilar OÑATE y GARCÍA DE LA RASILLA,

Departamento de Psicología Evolutiva y de la Educación.

Facultad de Educación. Universidad Complutense de Madrid.

Rector Royo Villanova, s/n.

28040. Madrid. España.

Tel. (34) 913946296

e-mail: piloñate@edu.ucm.es

Carmen ROSTAND QUIJADA,

Departamento de Didáctica y Organización Escolar

Facultad de Educación. Universidad Complutense de Madrid.

Rector Royo Villanova, s/n.

28040. Madrid. España.

Tel. (34) 913946170

e-mail: crostand@edu.ucm.es 